Article

\title{
Catalytic Fast Pyrolysis of Kraft Lignin over Hierarchical HZSM-5 and $H \beta$ Zeolites
}

\author{
Yadong Bi ${ }^{1}$, Xiaojuan Lei ${ }^{1}$, Guihua $\mathrm{Xu}^{1}$, Hui Chen ${ }^{1, *}$ and Jianli $\mathrm{Hu}^{2}$ \\ 1 Tianjin Key Laboratory of Organic Solar Cells and Photochemical Conversion, School of Chemistry and \\ Chemical Engineering, Tianjin University of Technology, Tianjin 300384, China; byd@tjut.edu.cn (Y.B.); \\ 153135311@stud.tjut.edu.cn (X.L.); 153135302@stud.tjut.edu.cn (G.X.) \\ 2 Department of Chemical and Biomedical Engineering, West Virginia University, Morgantown, \\ WV 26506, USA; john.hu@mail.wvu.edu \\ * Correspondence: tjge@tjut.edu.cn; Tel./Fax: +86-22-6021-4259
}

Received: 25 January 2018; Accepted: 11 February 2018; Published: 14 February 2018

\begin{abstract}
The hierarchical HZSM- 5 and $\mathrm{H} \beta$ zeolites were prepared by alkaline post-treatment methods adopting $\mathrm{Na}_{2} \mathrm{CO}_{3}, \mathrm{TMAOH} / \mathrm{NaOH}$ mixture, and $\mathrm{NaOH}$ as desilication sources, respectively. More mesopores are produced over two kinds of zeolites, while the micropores portion is well preserved. The mesopores formed in hierarchical $\mathrm{H} \beta$ zeolites were directly related to the basicity of the alkaline solution, indicating that $\mathrm{H} \beta$ zeolite is more sensitive to the alkaline post-treatment. The hierarchical HZSM-5 and $\mathrm{H} \beta$ zeolites are more active than the parent one for catalytic fast pyrolysis (CFP) of Kraft lignin. Hierarchical zeolites retained the function of acid catalysis, while additionally creating larger mesopores to ensure the entry of bulkier reactant molecules. The increase of the condensable volatiles yield can be attributed to the improvement of the mass transfer performance, which correlates well with the change of mesoporous surface area. In particular, the condensable volatiles yield for the optimized hierarchical $\mathrm{H} \beta$ reached approximately two times that of the parent $\mathrm{H} \beta$ zeolites. In contrast to the parent HZSM-5, the optimized hierarchical HZSM-5 zeolite significantly reduced the selectivity of oxygenates from $27.2 \%$ to $3.3 \%$.
\end{abstract}

Keywords: catalytic fast pyrolysis; Kraft lignin; hierarchical zeolites; HZSM-5; H $\beta$

\section{Introduction}

Lignocellulose is the most abundantly available raw material on the earth for the production of biofuels. It is mainly composed of carbohydrate polymers (cellulose, hemicellulose), and a cross-linked aromatic polymer (lignin). Bio-oils derived from lignocellulose pyrolysis are characterized by high oxygen content, high acidity, and high viscosity, which significantly limit its utilization in the existing petrochemical infrastructure [1]. Removing oxygen from raw materials efficiently is usually a challenge for the catalytic fast pyrolysis (CFP) of lignocellulose to produce a high-energy density fuel with good combustion performance [2]. Generally, pyrolysis vapors can be upgraded by catalytic conversion over solid acid catalysts such as zeolites to generate products of lower oxygen content [3].

As the most recalcitrant component of lignocellulose, lignin has a high resistance to chemical attacks such as pyrolysis [4]. Monomeric phenolic compounds are the primary pyrolysis products of lignin and easily recombine to produce oligomeric compounds [5]. Lignin-derived phenols, which are strongly adsorbed on zeolite acidic sites, could act as a coke precursor and form a large number of cokes [6]. In CFP process, coke formation not only leads to rapid deactivation caused by blocking zeolite pores, but also declines the carbon conversion efficiency. Compared with the other two components, although lignin itself is composed of aromatic polymer structure, it has the lowest aromatics yield and highest coking under the same CFP conditions [7]. 
Microporous zeolites such as HZSM-5 are known to be effective deoxygenation catalysts, which can convert pyrolysis vapors of lignocellulose directly to olefins and aromatics [7-14]. However, due to size exclusion or pore blockage, HZSM- 5 was invalid in the treatment of heavier feeds such as syringyl monolignols derived from CFP of lignin [13]. The diffusion and mass transfer resistance of molecules in and out of micropores often limit the space utilization in microporous zeolites; it is necessary to optimize the accessibility of zeolites to these components. Aluminosilicates possess a much larger pore size; however, CFP of lignin over this mesoporous material yields a similar aromatics and coke as HZSM-5 zeolite [15]. The relationship between the acidity and porosity of mesoporous aluminosilicates with product selectivity during CFP of lignin is hard to establish. The introduction of hierarchical zeolite, which has interconnected mesopores and micropores, is a promising approach for solving this problem [16-19]. Hierarchical zeolite retained the function of acid catalysis, while additionally creating larger mesopores to ensure the entry of bulkier reactant molecules. Puertolas had shown that the aromatics fraction for bio-oils conversion was correlated with the accessible Brønsted acid sites at the mesoporous surface for hierarchical zeolites [10]. Pinard had demonstrated that mesopores can be seen as "highways", where big molecules can diffuse to more accessible Brønsted sites on micropores [11]. A hierarchical zeolite presents much higher selectivity to mono-aromatics and stability upon coke deposit than microporous zeolite.

The most feasible preparation method for the hierarchical zeolite is a desilication of a microporous zeolite using an alkaline solution [16-19]. In this study, the influence of different alkaline desilication sources on the formation of intracrystalline mesopores through hydrolysis of the skeleton atom was investigated. The hierarchical HZSM- 5 and $\mathrm{H} \beta$ zeolites with moderate acidity and pore structure were successfully prepared by an optimized alkaline treatment. The CFP of lignin over hierarchical HZSM-5 and $\mathrm{H} \beta$ zeolites was analyzed on-line by Py-GC/MS technique, by evaluating the impact of mass transfer performance on the yield of condensable volatiles and the deoxidation effect.

\section{Results}

In order to create more open mesopores in the microporous zeolites, four different treatment methods were investigated. The alkaline post-processing adopted $\mathrm{Na}_{2} \mathrm{CO}_{3}$ (Treatment $\mathrm{A}$ ), $\mathrm{TMAOH} / \mathrm{NaOH}$ mixture (Treatment $\mathrm{B}$ ), and $\mathrm{NaOH}$ (Treatment $\mathrm{C}$ ) as desilication sources respectively, reacting at $65{ }^{\circ} \mathrm{C}$ for $1.5 \mathrm{~h}$. A sequential mild acid treatment with $\mathrm{HCl}$ was performed after desilication of zeolites with $\mathrm{NaOH}$ (Treatment D), in order to remove Lewis acid sites generated after mesoporosity introduction.

\subsection{Nitrogen Physisorption Characterization}

Table 1 summarizes the texture properties of HZSM- 5 zeolites obtained by different post-treatment methods. The parent HZSM- 5 is characterized by typical microporous material. The mesoporous surface area is only $18 \mathrm{~m}^{2} / \mathrm{g}$, which is negligible compared to the microporous surface area of $395 \mathrm{~m}^{2} / \mathrm{g}$. For HZSM- 5 after different alkaline treatments, the mesoporous surface area all approximately increase to about $34 \mathrm{~m}^{2} / \mathrm{g}$, while the corresponding microporous surface area decreases synchronously. A further mild $\mathrm{HCl}$ washing after desilication with $\mathrm{NaOH}$ makes little change to mesopores, but the microporous surface area was restored to $394 \mathrm{~m}^{2} / \mathrm{g}$ for HZSM-5-D. The changes of mesoporous volume and microporous volume in each sample were in accordance with the corresponding trends of specific surface area. Figure 1 shows the pore size distribution of HZSM- 5 zeolites obtained by different post-treatment methods, which was calculated according to the adsorption branch of isotherms using the BJH method. It is obvious that the microporous size distribution of parent HZSM-5 is very concentrated. Alkaline treatment has no effect on the location of the distribution maximum for micropore, but the intensity decreases. For hierarchical HZSM-5, there are a small amount of mesopores formed in a pore width of 2-6 nm. Consistent with the specific surface area, the HZSM-5-D possess slightly more micropores than parent HZSM-5. 


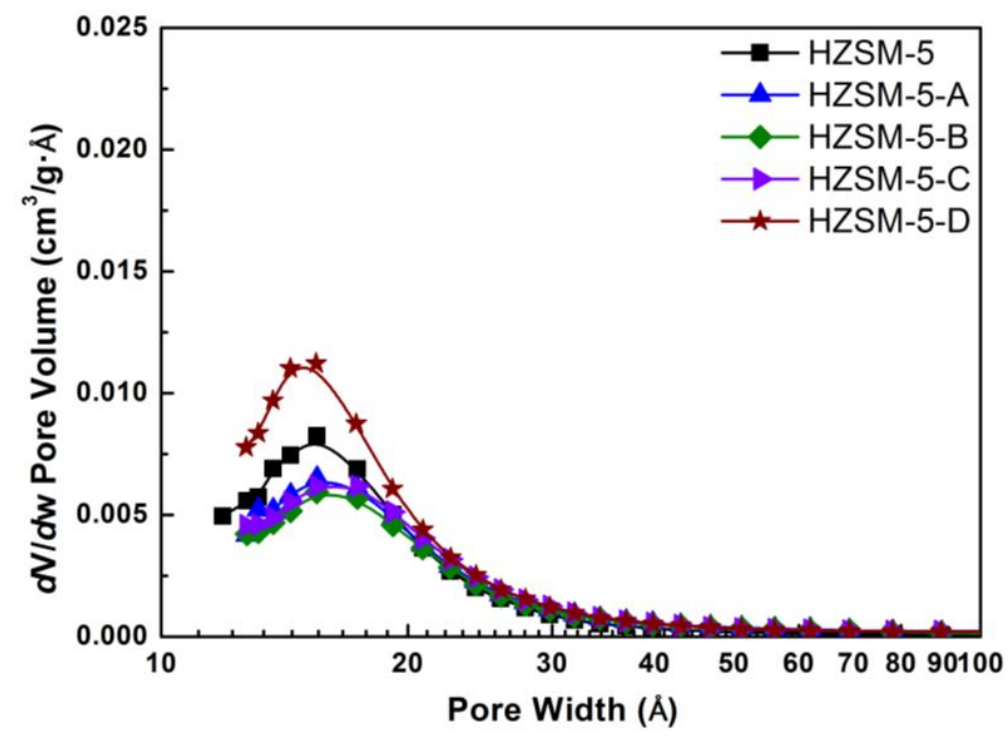

Figure 1. Pore size distribution of parent HZSM-5 and the hierarchical HZSM-5 obtained by different post-treatment methods.

Table 1. Physicochemical properties of parent HZSM-5 and the hierarchical HZSM-5 obtained by different post-treatment methods.

\begin{tabular}{cccccc}
\hline Sample & $S_{\text {Meso }}\left(\mathbf{m}^{\mathbf{2}} / \mathbf{g}\right)$ & $S_{\text {Micro }}\left(\mathbf{m}^{2} / \mathbf{g}\right)$ & $V_{\text {Meso }}\left(\mathrm{cm}^{\mathbf{3}} / \mathbf{g}\right)$ & $V_{\text {Micro }}\left(\mathrm{cm}^{\mathbf{3}} / \mathbf{g}\right)$ & Rel. Crystal. (\%) \\
\hline HZSM-5 & 18 & 395 & 0.04 & 0.17 & 100 \\
HZSM-5-A & 34 & 363 & 0.07 & 0.15 & 85 \\
HZSM-5-B & 33 & 351 & 0.07 & 0.15 & 79 \\
HZSM-5-C & 35 & 369 & 0.08 & 0.16 & 91 \\
HZSM-5-D & 34 & 394 & 0.08 & 0.17 & 81 \\
\hline
\end{tabular}

Table 2 summarizes the texture properties of $\mathrm{H} \beta$ zeolites obtained by different post-treatment methods. The specific surface area of parent $\mathrm{H} \beta$ is larger than HZSM-5, and contains a certain amount of mesopores itself $\left(86 \mathrm{~m}^{2} / \mathrm{g}\right)$. Different alkaline treatments process had varying impacts on the formed mesopores. There is only a slight increase in the mesoporous surface area of $\mathrm{H} \beta-\mathrm{A}$ and $\mathrm{H} \beta-\mathrm{B}$. The mesoporous surface area of $\mathrm{H} \beta-\mathrm{C}$ is twice as large as parent $\mathrm{H} \beta$, while the microporous surface area decreased correspondingly. The mesoporous surface area of $\mathrm{H} \beta$-D further increased, while the microporous surface area remained at $421 \mathrm{~m}^{2} / \mathrm{g}$. As can be seen from pore size distribution in Figure 2, the hierarchical $\mathrm{H} \beta$ still retains a large amount of micropores, while the newly-formed mesopores are not very concentrated. For $\mathrm{H} \beta-\mathrm{A}$ and $\mathrm{H} \beta-\mathrm{B}$, the additional mesopores are mainly distributed in the range of $2-4 \mathrm{~nm}$, while for $\mathrm{H} \beta-\mathrm{C}$ and $\mathrm{H} \beta-\mathrm{D}$, the pore size distribution of the additional mesopores is shifted to larger pore diameters (3-6 $\mathrm{nm}$ and $4-9 \mathrm{~nm}$, respectively).

Table 2. Physicochemical properties of parent $\mathrm{H} \beta$ and the hierarchical $\mathrm{H} \beta$ obtained by different post-treatment methods.

\begin{tabular}{cccccc}
\hline Sample & $S_{\text {Meso }}\left(\mathbf{m}^{\mathbf{2}} / \mathbf{g}\right)$ & $S_{\text {Micro }}\left(\mathbf{m}^{2} / \mathbf{g}\right)$ & $V_{\text {Meso }}\left(\mathbf{c m}^{\mathbf{3}} / \mathbf{g}\right)$ & $V_{\text {Micro }}\left(\mathrm{cm}^{\mathbf{3}} / \mathbf{g}\right)$ & Rel. Crystal. (\%) \\
\hline H $\beta$ & 86 & 545 & 0.22 & 0.21 & 100 \\
H $\beta-A$ & 116 & 535 & 0.28 & 0.21 & 70 \\
H $\beta-B$ & 117 & 555 & 0.32 & 0.22 & 80 \\
H $\beta-C$ & 171 & 450 & 0.36 & 0.18 & 67 \\
H $\beta-D$ & 232 & 421 & 0.37 & 0.16 & 72 \\
\hline
\end{tabular}




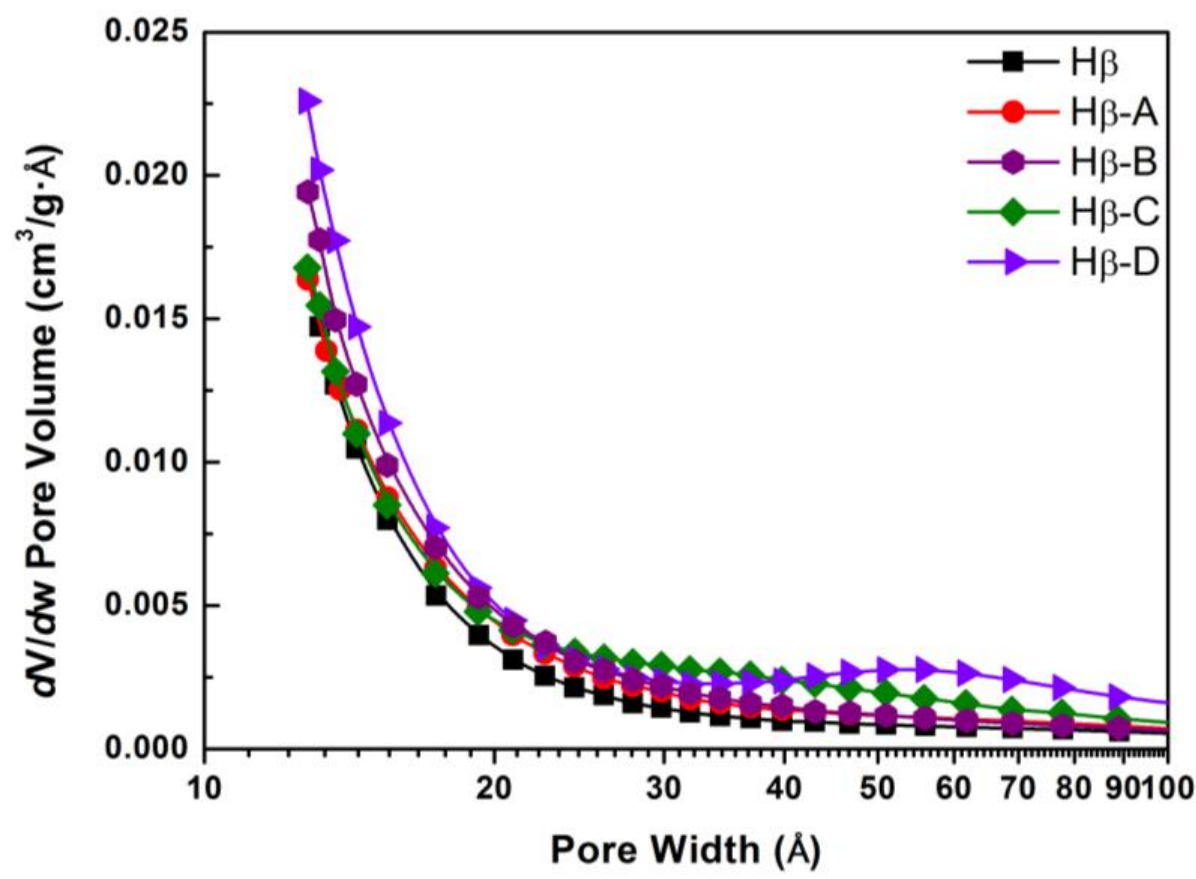

Figure 2. Pore size distribution of parent $\mathrm{H} \beta$ and the hierarchical $\mathrm{H} \beta$ obtained by different post-treatment methods.

Under alkaline treatment conditions, larger mesopores are created by amorphization and skeleton atom leaching. Compared with the strong alkaline nature of $\mathrm{NaOH}$ solution, the treatment process using $\mathrm{Na}_{2} \mathrm{CO}_{3}$ and TMAOH/NaOH solution is milder in a weak alkaline environment. Zhao studied the effect of different alkaline treatment conditions on hierarchical HBEA zeolites [16]. In $\mathrm{Na}_{2} \mathrm{CO}_{3}$ solution, the formation of intracrystalline mesopores was not selective. For TPAOH/NaOH treatment, the pore formation process showed a moderate desilication in the intra-mesopores, because $\mathrm{TPA}^{+}$ions bound to the zeolite surface in alkaline environment act as suitable pore-directing agents. Pure $\mathrm{NaOH}$ treatment provides no affinity to the zeolite surface, resulting in the unselective dissolution of the crystals on the unprotected surface. We noticed that there was an approximate mesoporous surface area for the hierarchical HZSM- 5 zeolites under different alkaline treatment conditions. However, the surface area of mesopores formed in hierarchical $\mathrm{H} \beta$ zeolites was directly related to the basicity of alkaline solution. More mesopores are produced in the higher alkaline $\mathrm{NaOH}$ solution, while the micropores portion is well preserved. The main reason may be due to the different pore structure of the two zeolites. HZSM- 5 contains 10-membered ring channels $(0.51 \mathrm{~nm} \times 0.55 \mathrm{~nm}$ and $0.53 \mathrm{~nm} \times 0.56 \mathrm{~nm})$, whereas $\mathrm{H} \beta$ contains 12-membered ring channels $(0.66 \mathrm{~nm} \times 0.67 \mathrm{~nm}$ and $0.56 \mathrm{~nm} \times 0.56 \mathrm{~nm}$ ). It is obvious that $\mathrm{H} \beta$ zeolite is more sensitive to the alkaline post-treatment.

\subsection{Structural XRD Characterization}

Figure 3 shows the XRD patterns for parent HZSM- 5 and the hierarchical HZSM- 5 obtained by different post-treatment methods. Figure 4 shows the XRD patterns for parent $\mathrm{H} \beta$ and the hierarchical $\mathrm{H} \beta$ obtained by different post-treatment methods. The hierarchical zeolites all possess the typical diffraction peak original features of the parent one, indicating the crystal structure was basically maintained after alkaline treatments. At the same time, the intensity of the diffraction peak decreased to a certain extent, due to the decrease of the relative crystallinity for hierarchical zeolites. The relative crystallinity was obtained according to the intensity of the strongest diffraction peak, assuming that the relative crystallinity of the parent zeolites was $100 \%$.For example, after desilication using $\mathrm{NaOH}$ solution, the relative crystallinity of $\mathrm{H} \beta-\mathrm{C}$ was only $67 \%$ of the parent $\mathrm{H} \beta$. 


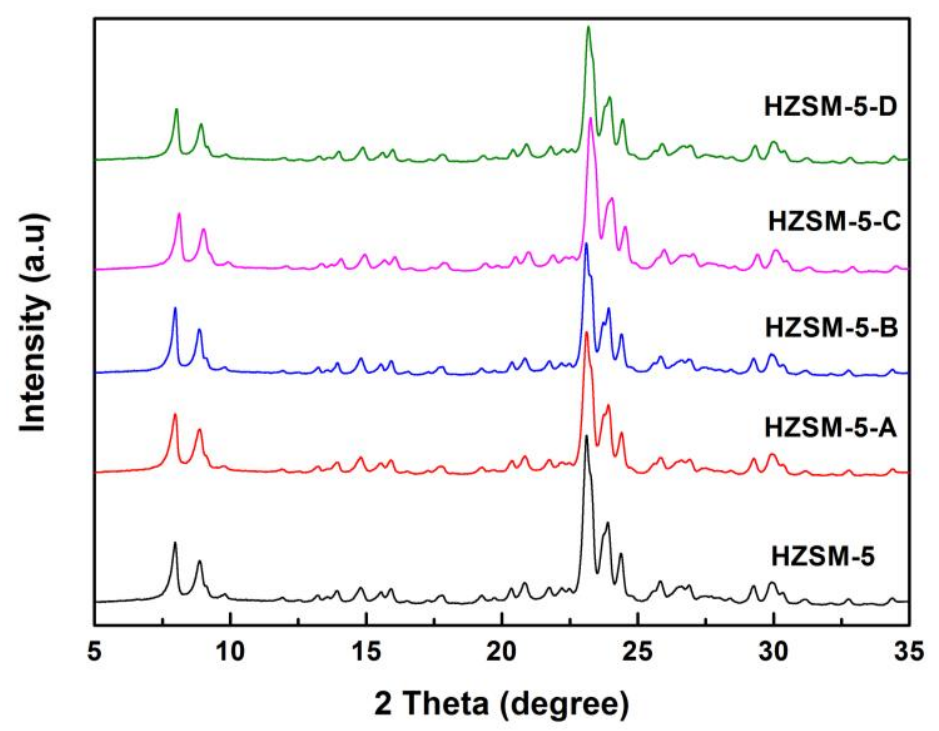

Figure 3. XRD patterns for parent HZSM-5 and the hierarchical HZSM-5 obtained by different post-treatment methods.



Figure 4. XRD patterns for parent $H \beta$ and the hierarchical $H \beta$ obtained by different post-treatment methods.

\section{3. $\mathrm{NH}_{3}-\mathrm{TPD}$ Characterization}

Figure 5 shows the $\mathrm{NH}_{3}$-TPD patterns of parent HZSM- 5 and the hierarchical HZSM- 5 obtained by different post-treatment methods. Figure 6 shows the $\mathrm{NH}_{3}$-TPD patterns of parent $\mathrm{H} \beta$ and the hierarchical $\mathrm{H} \beta$ obtained by different post-treatment methods. Two ammonia desorption peaks appear in all zeolites. The low temperature peak is derived from the weakly adsorbed ammonia molecules via hydrogen bonding, instead of the acid sites [19]. The high temperature peaks can be ascribed to strong Brønsted acid sites. It had been previously reported that Brønsted acid sites mainly exist over hierarchical zeolites formed in the partial desilication [18]. $\mathrm{Na}^{+}$ions existed in the cationic sites of zeolite during alkaline treatment process, which could be removed by following ion exchanging with $\mathrm{NH}_{4}{ }^{+}$; thus, the Brønsted acidity could be recovered. 


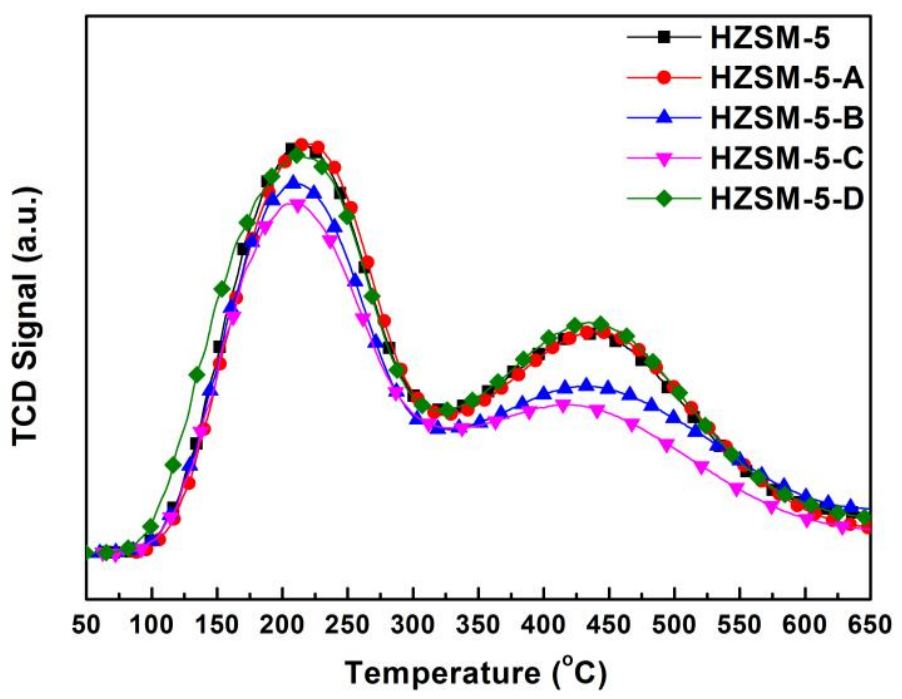

Figure 5. $\mathrm{NH}_{3}$-TPD profiles for parent HZSM-5 and the hierarchical HZSM-5 obtained by different post-treatment methods.

Different alkaline treatments processes did not change the low temperature peak of the hierarchical HZSM-5. The high temperature peak remained essentially in the original position, indicating that alkaline treatment has tiny effect on the strength of the Brønsted acid sites. The peak area slightly decreased for HZSM-5-B and HZSM-5-C, indicating partial desilication reduces the number of Brønsted acid sites. The $\mathrm{NH}_{3}$-TPD patterns of the hierarchical $\mathrm{H} \beta$ exhibit similar desorption peaks to the parent one, indicating the alkaline treatment of $\mathrm{H} \beta$ Zeolites may not significantly decrease the acidity. For the hierarchical zeolites, we also noted that the loss of relative XRD crystallinity did not correlate well with the amount of acid sites, especially for HZSM-5-C and H $\beta$-A. The characteristic tetrahedrally coordinated aluminosilicate framework of zeolites results in Brønsted acid sites. In the harsh treatment condition of strong alkaline environment, larger mesopores are created by a combination of amorphization and framework atom leaching, which both affect the amount of acid sites. The relationship between the amount of acid sites determined from $\mathrm{NH}_{3}$-TPD and relative crystallinity is more complicated.

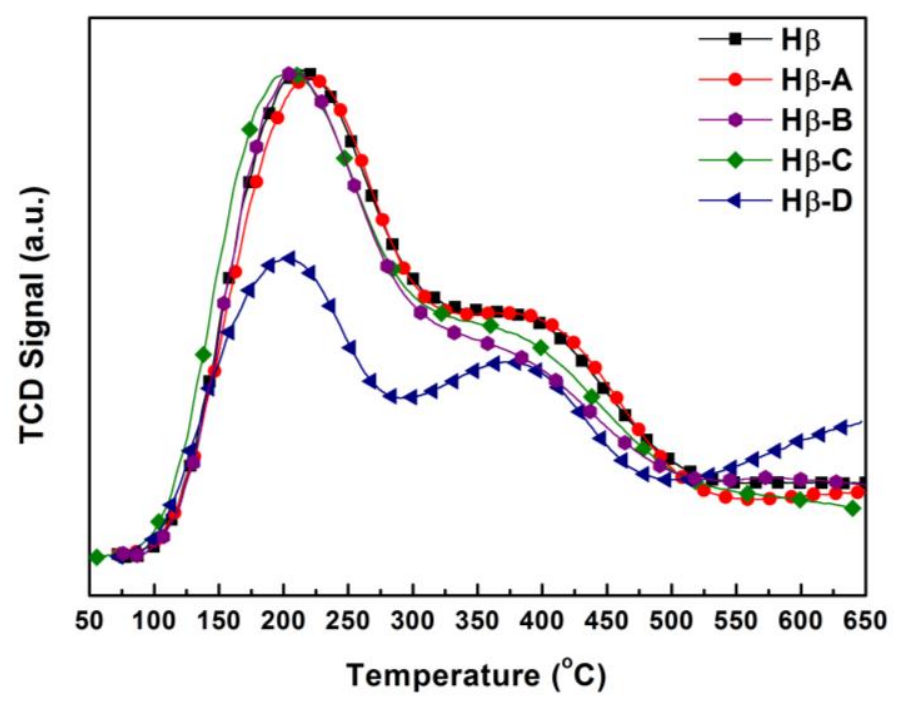

Figure 6. $\mathrm{NH}_{3}$-TPD profiles for parent $\mathrm{H} \beta$ and the hierarchical $\mathrm{H} \beta$ obtained by different post-treatment methods. 


\subsection{Catalytic Fast Pyrolysis of Kraft Lignin}

Lignin is very chemically inert, due to its complex three-dimensional network structure formed by different non-phenolic phenylpropanoid units, which were linked with a variety of $\mathrm{C}-\mathrm{O}$ and $\mathrm{C}-\mathrm{C}$ bonds $[2,4,5]$. Pyrolysis can destroy these phenyl-propane units in the polymer lattice. As shown in Figure 7, the pyrograms of lignin over parent HZSM-5 and H $\beta$ Zeolites were compared with those of non-catalytic fast pyrolysis. The yield of the condensable volatiles during Py-GC/MS experiments is semi-quantitatively evaluated by the sum of the absolute peak area of the total ion chromatogram peak (calibrated with the precise lignin sample weight), while the selectivity of a certain category of compound is represented by the percentage of peak area measured in total area. The light gases derived from the deoxygenation of oxygenates during CFP of lignin, mainly $\mathrm{CO}_{2}, \mathrm{CO}$, and other non-condensable gas, are not included in the sum of the absolute peak areas of condensable liquid products. As reported in previous studies by Bokhoven [15], the yield of light gases was about $5 \%$ when the lignin was pyrolyzed at $650{ }^{\circ} \mathrm{C}$ on different zeolites catalysts. Because the lignin has a high resistance to pyrolysis, the polymer structure can only be depolymerized into aromatic monomers at the pyrolysis temperature of $600{ }^{\circ} \mathrm{C}$ in this work; thus, the $\mathrm{C}-\mathrm{C}$ bond will not be further broken to produce smaller molecules of light gases. It has also been reported previously that the yield of light gases produced by lignin pyrolysis is much lower than that of cellulose and hemicellulose [20]. Therefore, in the pyrolysis conditions of this work, pyrolysis products are mainly the condensable volatiles and coke correlating with each other. The products from lignin pyrolysis are very complex. It becomes very difficult to measure individual component. The retention time and the characteristic ion fragments of each compound in the total ion current chromatogram are shown in Table S1. Non-CFP of lignin mainly produces oxygen-containing species with very few aromatic hydrocarbons. During the process of lignin pyrolysis, Bokhoven verified that depolymerized lignin products undergo successive reactions to form phenol alkoxy ketones, phenol alkoxy, phenols, aromatic alkoxy, and, finally, aromatic hydrocarbon [14,15]. The presence of zeolites greatly changed the composition of pyrolysis products, leading to improved deoxygenation of the high oxygen-containing compounds into aromatics. The GC-detected condensable pyrolysis products were divided into 4 categories: oxygenates (predominantly phenols, guaiacols, and syringols), monocyclic aromatics (BTX), naphthalene, and polycyclic aromatic hydrocarbons (PAH). The retention time and the characteristic ion fragments of each compound in the total ion current chromatogram are shown in Table S2.

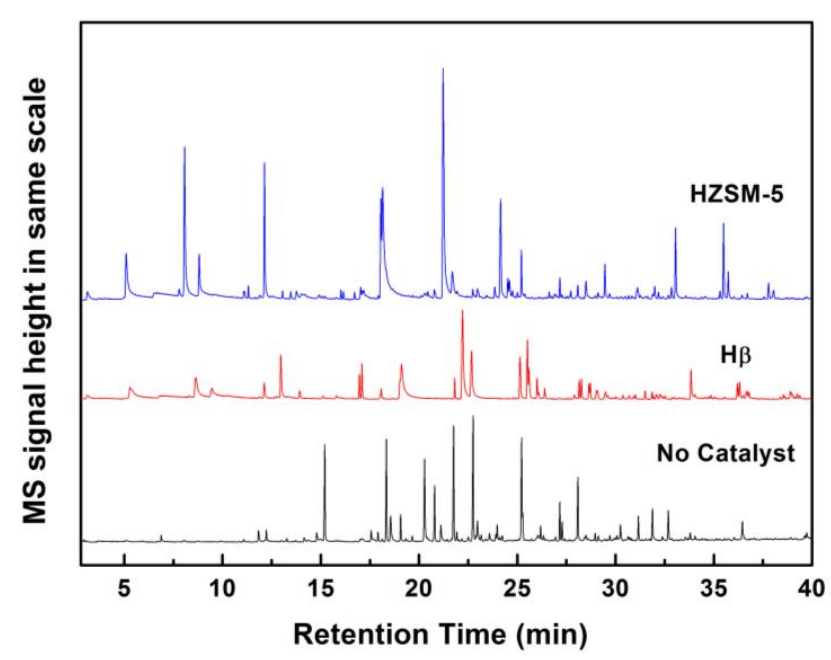

Figure 7. The pyrograms (Py-GC/MS) of catalytic fast pyrolysis of Kraft lignin over parent HZSM-5 and $\mathrm{H} \beta$ Zeolites. Experimental conditions: pyrolysis temperature of $500{ }^{\circ} \mathrm{C}, \mathrm{Kraft}$ lignin $0.3 \mathrm{mg}$, catalyst-to-lignin ratio of 10:1. 
The acid sites of zeolites can promote deoxygenation, decarboxylation, and decarbonylation, as well as cleavage, oligomerization, alkylation, isomerization, cyclization, and aromatization, to further convert the depolymerization products of lignin. Over the parent HZSM- 5 and H $\beta$ Zeolites, there are significant differences in the selectivity of condensable volatiles. Using HZSM-5 catalyst, $27.2 \%$ of oxygenates still exist in the condensable volatiles, mainly in trimethoxybenzene. On $\mathrm{H} \beta$ zeolite, oxygenates almost disappeared completely, only $1 \%$. The deoxygenation effect of $\mathrm{H} \beta$ is much higher than that of HZSM-5. Considering the difference in pore structure between the two zeolites, more lignin-derived oxygenates can diffuse into the larger pores of $H \beta$, even larger molecules trimethoxybenzene; thereby, most of oxygenates can be effectively converted. It has also been reported previously that HZSM- 5 is invalid for the conversion of bulkier lignin monomers due to size exclusion or pore plugging, while $\mathrm{H} \beta$ is very effective for deoxygenation of lignin-derived oxygenates [13]. Zeolite strong acid sites are not the unique factor to achieve high conversion and selectivity to aromatics. The two most essential parameters are diffusion and the active site.

The yield of the condensable volatiles for the CFP over parent HZSM-5zeolite is much higher than that of non-CFP of lignin. The reason is tentatively speculated that the microporous zeolites help to stabilize reactive intermediates derived during lignin pyrolysis, which otherwise readily recombine to form char. On the other hand, Hßis not as effective as HZSM-5 in improving the yield of the condensable volatiles. The yields of condensable volatiles on parent $\mathrm{H} \beta$ zeolite are even lower than those of non-CFP. It is tentatively speculated that the reason for this is that less coke is present on the surface of HZSM-5, which is mainly derived from large size PAH molecule. It has been reported previously that the amount of coke derived from CFP of lignin is related to the pore size, and the larger pore size of the $\mathrm{H} \beta$ zeolites is favorable for the formation of coke occurring from polymerization reactions [13]. For HZSM-5 zeolite, the formation of large condensed molecules from side reactions was inhibited due to the smaller pore size. For $\mathrm{H} \beta$ zeolite, the concentration of $\mathrm{PAH}$ in the condensable volatiles is twice as much as HZSM-5. There is a considerable amount of 3 and 4 ring aromatics produced over $\mathrm{H} \beta$ zeolite, indicating that these large $\mathrm{PAH}$ are not hindered by the steric hindrance.

Figure 8 shows the yield of the condensable volatiles for lignin CFP over HZSM- 5 zeolites obtained by different post-treatment methods. Compared with parent HZSM-5, the yield of the condensable volatiles on hierarchical HZSM-5 zeolites increased slightly, which is basically in accordance with the increase of mesoporous surface area. As shown in Figure 9, the alkaline desilication treatment improved considerably the selectivity in aromatics hydrocarbon over hierarchical HZSM-5 zeolites. Compared with pure HZSM-5, the selectivity in naphthalene and PAH for hierarchical HZSM-5 zeolite is increased without affecting the yields in BTX. The most significant distinction for hierarchical HZSM-5 zeolite is the sharp reduction of oxygenates in the condensable volatiles, especially for HZSM-5-D, only $3.3 \%$. Oxygenates are significantly reduced, while the amount of aromatic hydrocarbons increased. The formation of mesopores after desilication enhances a faster diffusion of reactants into the active surface and of products out of the zeolite particles. The introduction of mesopores in hierarchical HZSM- 5 zeolite makes the larger oxygenates molecules diffuse into the pores and become effectively deoxygenated under the catalysis functions of Brønsted acid sites. As the main active sites for biomass pyrolysis vapors conversion, the remained Brønsted acid sites mainly presented in the micropores are more accessible in the hierarchical HZSM-5 zeolite. The deoxidation of oxygenates derived from lignin pyrolysis was effectively improved, which could be tentatively ascribed to the suppression of mass transfer resistance over hierarchical HZSM-5 zeolite. We speculated that the obtained deoxidation product can quickly diffuse out of the pore, avoiding the formation of unnecessary coke due to molecules condensation. 


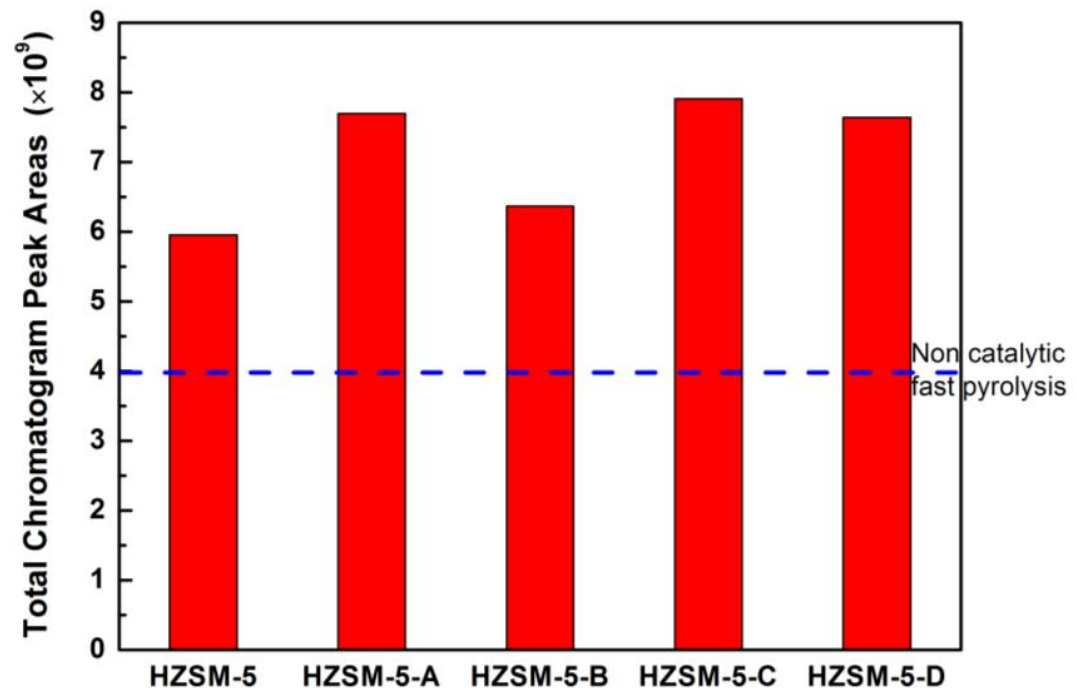

Figure 8. The total yield of the condensable volatiles fromcatalytic fast pyrolysis of Kraft lignin over parent HZSM-5 and the hierarchical HZSM- 5 obtained by different post-treatment methods. Experimental conditions: pyrolysis temperature of $500{ }^{\circ} \mathrm{C}$, Kraft lignin $0.3 \mathrm{mg}$, catalyst-to-lignin ratio of 10:1.

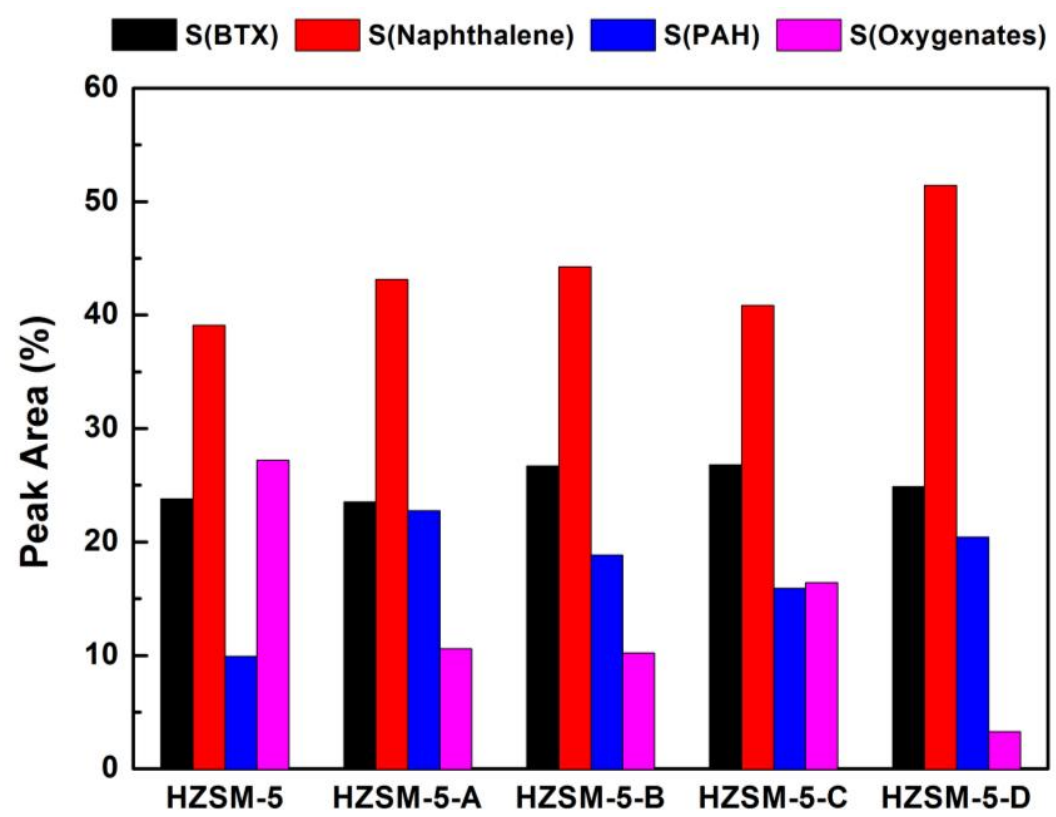

Figure 9. The selectivity of various volatile products from catalytic fast pyrolysis of Kraft lignin over parent HZSM-5 and the hierarchical HZSM- 5 obtained by different post-treatment methods. Experimental conditions: pyrolysis temperature of $500{ }^{\circ} \mathrm{C}, \mathrm{Kraft}$ lignin $0.3 \mathrm{mg}$, catalyst-to-lignin ratio of $10: 1$.

Figure 10 shows the yield of the condensable volatiles for lignin catalytic fast pyrolysis over $\mathrm{H} \beta$ zeolites obtained by different post-treatment methods. The hierarchical $\mathrm{H} \beta$ zeolite is much more active than the parent one. The yield of the condensable volatiles gradually increases from $H \beta-A$ to $H \beta-D$, which correlates well with the change of mesoporous surface area. In particular, the condensable product yield for $\mathrm{H} \beta$-D is 2 times that of the parent $\mathrm{H} \beta$. The increase of the yield can also be attributed to the improvement of the mass transfer performance, because the alkaline desilication treatments are more effective for the formation of mesopores on hierarchical $\mathrm{H} \beta$ zeolite. Similar to the case of 
hierarchical zeolite HZSM-5, the introduction of mesopores mainly promotes the diffusion of molecules in and out of the active sites during the pyrolysis process. The yield of condensable volatiles over parent $\mathrm{H} \beta$ is lower than that of parent HZSM-5. Considering that the parent HZSM- 5 contains hardly any mesopore, the mesopores present in the parent $\mathrm{H} \beta$ itself had tiny effect on inhibiting carbon deposition. It is speculated that the additional mesopores in hierarchical $\mathrm{H} \beta$ zeolite may be interconnected with micropores. The hierarchical pore structures can improve the utilization of micropores, due to the promoted mass transfer performance and the more accessible surface Brønsted acid sites. As shown in Figure 11, the selectivity in oxygenates for hierarchical $\mathrm{H} \beta$ zeolites is slightly increased without affecting the yields in aromatic hydrocarbons. The improved activity of the hierarchical zeolite is ascribed to the synergistic effect between the presence of Brønsted sites and accessible mesopores.

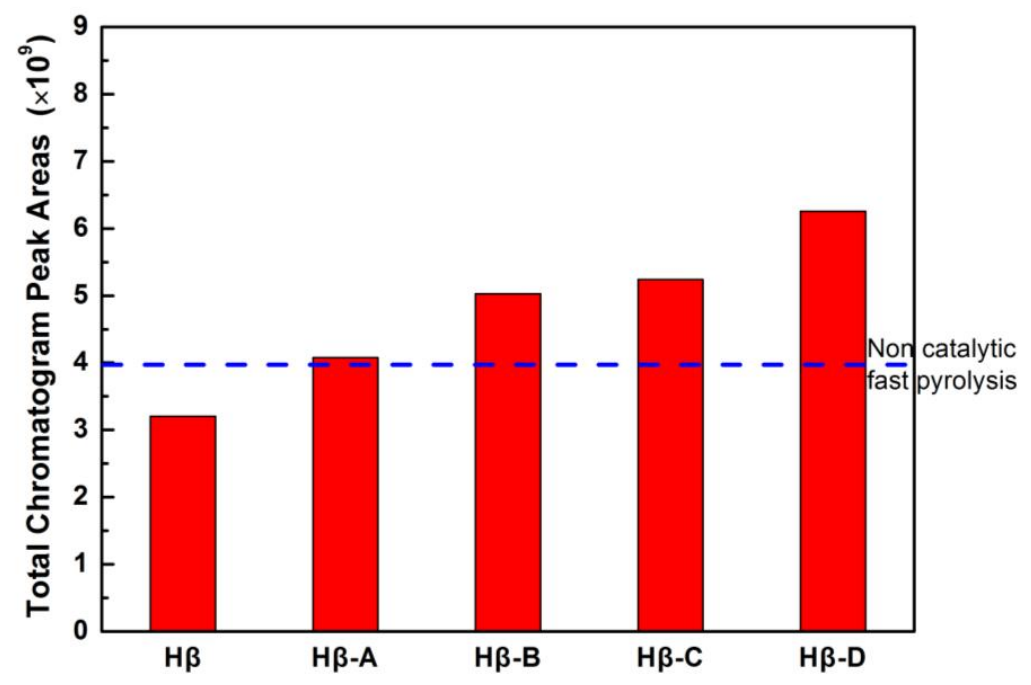

Figure 10. The total yield of the condensable volatiles fromcatalytic fast pyrolysis of Kraft lignin over parent $\mathrm{H} \beta$ and the hierarchical $\mathrm{H} \beta$ obtained by different post-treatment methods. Experimental conditions: pyrolysis temperature of $500{ }^{\circ} \mathrm{C}$, Kraft lignin $0.3 \mathrm{mg}$, catalyst-to-lignin ratio of 10:1.

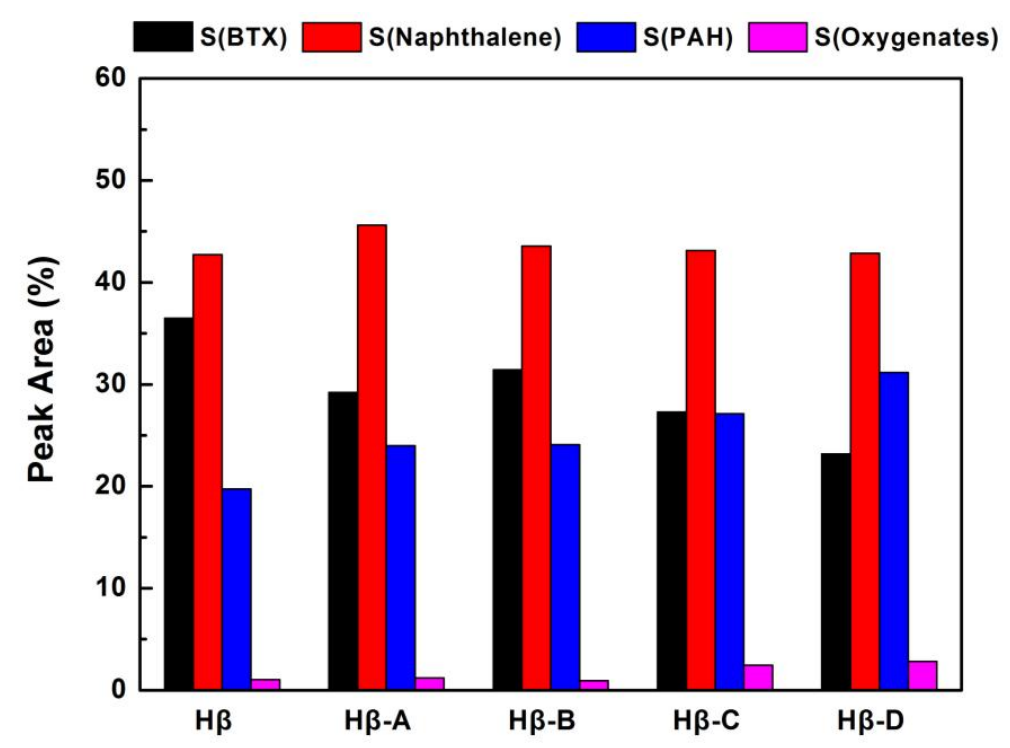

Figure 11. The selectivity of various volatile products from catalytic fast pyrolysis of Kraft lignin over parent $\mathrm{H} \beta$ and the hierarchical $\mathrm{H} \beta$ obtained by different post-treatment methods. Experimental conditions: pyrolysis temperature of $500{ }^{\circ} \mathrm{C}$, Kraft lignin $0.3 \mathrm{mg}$, catalyst-to-lignin ratio of 10:1. 


\section{Materials and Methods}

\subsection{Materials and Chemicals}

Commercial Kraft lignin (product number 471003, Sigma-Aldrich, Saint Louis, MO, USA), $\mathrm{NaOH}$ ( $\geq 96 \%$ AR assay, Aladdin, Shanghai, China), $\mathrm{HCl}$ (36-38\% AR assay), $\mathrm{H} \beta$ zeolite (Si: $\mathrm{Al}=20$, Nankai University Catalyst Co. Ltd., Tianjin, China), HZSM-5 zeolite (Si:Al = 25, Nankai University Catalyst Co. Ltd., Tianjin, China) $\mathrm{NH}_{4} \mathrm{NO}_{3}$ ( $\geq 96 \%$ AR assay, Aladdin, Shanghai, China), $\mathrm{Na}_{2} \mathrm{CO}_{3}(99 \%$ AR assay, Aladdin, Shanghai, China), TMAOH (25\% of water AR assay, Aladdin, Shanghai, China).

\subsection{Catalyst Preparation}

The hierarchical zeolites were prepared by alkaline post-processing method using $\mathrm{Na}_{2} \mathrm{CO}_{3}$, $\mathrm{TMAOH} / \mathrm{NaOH}$ mixture, and $\mathrm{NaOH}$ as desilication sources, respectively. Typically, $4.0 \mathrm{~g}$ HZSM- 5 or $\mathrm{H} \beta$ powders were added into following aqueous solutions.

TreatmentA: $133 \mathrm{~mL} 0.1 \mathrm{M} \mathrm{Na}_{2} \mathrm{CO}_{3}$ alkaline aqueous solution;

Treatment B: $133 \mathrm{~mL}$ mixed alkaline solution $\left(\mathrm{C}_{\mathrm{TMAOH}} / \mathrm{C}_{\mathrm{OH}^{-}}{ }^{-}=0.6\right)$, which contained TMAOH (5.8190 g, $25 \mathrm{wt} \%)$ and $\mathrm{NaOH}(0.4380 \mathrm{~g})$;

Treatment C: $133 \mathrm{~mL} 0.1 \mathrm{M} \mathrm{NaOH}$ alkaline solution.

Then, the suspension was heated to $65^{\circ} \mathrm{C}$ and stirred for $1.5 \mathrm{~h}$. After being cooled down to room temperature, the solid was recovered by centrifugation and washed thoroughly with deionized water.

Treatment D: Selected $\mathrm{NaOH}$-treated samples were treated in aqueous $\mathrm{HCl}$ solution $(0.1 \mathrm{M}$, $100 \mathrm{~cm}^{3} / \mathrm{g}_{\text {zeolite }}$ ), and then the above stirring, cooling, centrifugation, and washing procedure were repeated.

The recovered solid sample was further exchanged three times with an aqueous solution of $\mathrm{NH}_{4} \mathrm{NO}_{3}(1.0 \mathrm{M}, 100 \mathrm{~mL})$, followed by drying at $80^{\circ} \mathrm{C}$ for $12 \mathrm{~h}$ and calcination in air to obtain the H-format $550{ }^{\circ} \mathrm{C}$ for $4 \mathrm{~h}$. The hierarchical HZSM-5 was denoted as HZSM-5-X, in which $\mathrm{X}$ was the corresponding alkaline post-processing method (treatment $\mathrm{A}$ or $\mathrm{B}$ or $\mathrm{C}$ or $\mathrm{D}$ ) and so on.

\subsection{Catalyst Characterization}

$\mathrm{N}_{2}$ adsorption-desorption isotherms were measured with Automatic physical adsorption instrument at $77 \mathrm{~K}$ (TriStar 3020, Micromeritics, Norcross, GA, USA). Prior to analysis, each sample was degassed under dynamic vacuum (VacPrep 061) at $300{ }^{\circ} \mathrm{C}$ for $4 \mathrm{~h}$. Pore size distribution was determined from the adsorption branch of isotherm, using the Barrett-Joyner-Halenda (BJH) Analysis. The Brunuer-Emmett-Teller (BET) method was used to estimate the total surface area $\left(0.01<p / p_{0}<0.08\right)$. The $t$-plot method was adopted to distinguish mesopores from micropores.

X-ray powder diffraction (XRD) patterns of the prepared samples were measured on a Philips CM-1 $(\mathrm{Cu} \mathrm{K} \alpha, \lambda=0.1543 \mathrm{~nm})$ powder X-ray diffractometer (Panalytical, Almelo, The Netherlands). Typically, the data was collected from $5^{\circ}$ to $70^{\circ}(2 \theta)$ for conventional wide-angle XRD patterns. The software X'Pert Highscore (Version: 1.0e, Panalytical, Almelo, The Netherlands, 2003) was used to perform microstructure analysis.

Temperature-programmed desorption of $\mathrm{NH}_{3}\left(\mathrm{NH}_{3}-\mathrm{TPD}\right)$ was carried out in an automatic chemisorb analyzer (ChemiSorb 2720, Micromeritics, Norcross, GA, USA). One hundred milligrams of each sample was introduced into a U-shaped tubular quartz reactor. Each sample was first treated at $500{ }^{\circ} \mathrm{C}$ for $1 \mathrm{~h}$ and then cooled down to room temperature in $\mathrm{He} . \mathrm{NH}_{3}$ was absorbed at $120{ }^{\circ} \mathrm{C}$ for $30 \mathrm{~min}(5 \mathrm{~mL} / \mathrm{min})$ of $10 \% \mathrm{NH}_{3} / \mathrm{He}$ followed by a He purge. TPD experiments were performed under a flow of $\mathrm{He}(25 \mathrm{~mL} / \mathrm{min})$ from 120 to $700{ }^{\circ} \mathrm{C}$ at a constant heating rate $\left(10^{\circ} \mathrm{C} / \mathrm{min}\right)$. The desorbed $\mathrm{NH}_{3}$ was monitored with a thermal conductivity detector (TCD).

\section{4. $P y-G C / M S$ Test}

Pyrolysis-gas chromatography-mass spectrometry (Py-GC/MS) study was performed at $500{ }^{\circ} \mathrm{C}$ using a micro-furnace system (PY-3030D, Frontier Laboratories, Fukushima, Japan) installed with a gas 
chromatograph (GC) (7890A, Agilent Technologies, Santa Clara, CA, USA). A mass spectrometer (MS) (5975C, Agilent Technologies, Santa Clara, CA, USA) was used to analyze the products. The injector temperature was kept at $300^{\circ} \mathrm{C}$ with a 1:100 split ratio. Analysis of condensable volatiles for lignin catalytic fast pyrolysis was performed using UA-5 Ultra ALLOY ${ }^{\circledR}$ Capillary Column $(30 \mathrm{~m} \times 0.25 \mathrm{~mm}$ and $0.250 \mu \mathrm{m}$ film thickness, with a stationary phase consisting of $5 \%$ diphenyldimetyl polysiloxane) with Helium as carrier gas of $1.0 \mathrm{~mL} / \mathrm{min}$ flow rate. The GC oven temperature program began with $40{ }^{\circ} \mathrm{C}$ (holding $3 \mathrm{~min}$ ) to $280^{\circ} \mathrm{C}$ with the heating rate of $5^{\circ} \mathrm{C} / \mathrm{min}$. The final temperature was held for $4 \mathrm{~min}$. The temperature of the GC/MS interface was held at $300{ }^{\circ} \mathrm{C}$, and the mass spectrometer was operated in EI mode at $70 \mathrm{eV}$. The mass range from $\mathrm{m} / \mathrm{z} 29$ to 350 was scanned at $4.37 \mathrm{scans} / \mathrm{s}$. Pyrolysis products were identified according to the NIST MS library and the literature data of bio-oils. In each experiment, about $0.3 \mathrm{mg}$ Kraft lignin (and $3 \mathrm{mg} \mathrm{HZSM}-5$ or $\mathrm{H} \beta$ zeolites for catalytic pyrolysis) were placed in a sample cup, and for each sample, experiments were conducted at least three times to confirm the reproducibility of the reported procedures.

\section{Conclusions}

Lignin is the most recalcitrant component of lignocellulose, which has a high resistance to pyrolysis. A large number of cokes derived from CFP of lignin usually lead to rapid deactivation of zeolites, which restricted the practical application of lignocellulose pyrolysis due to the loss of carbon conversion efficiency. The diffusion and mass transfer resistance of heavier feeds often limit the space utilization in microporous zeolites. The hierarchicalHZSM- 5 and $\mathrm{H} \beta$ zeolites, which have interconnected mesopores and micropores, were prepared successfully by alkaline desilication methods to optimize the accessibility to these big molecules. We noticed that there was an approximate mesoporous surface area for the hierarchical HZSM- 5 zeolites under the treatment condition of different alkaline desilication sources. However, the surface area of mesopores formed in the hierarchical $\mathrm{H} \beta$ zeolites was directly related to the basicity of alkaline solution. The hierarchical zeolites all maintained the original crystallographic structure of the parent one. The CFP of lignin over the hierarchical HZSM-5 and H $\beta$ zeolites was analyzed on-line by Py-GC/MS technique. The deoxidation of oxygenates derived from lignin pyrolysis was effectively improved without the formation of extra coke, which could be ascribed to the suppression of mass transfer resistance over hierarchical HZSM- 5 zeolite. The yield of the condensable volatiles over hierarchical $\mathrm{H} \beta$ zeolite gradually increases, which correlates well with the change of mesoporous surface area. The improved activity of the hierarchical zeolites is ascribed to the synergistic effect between the presence of Brønsted sites and accessible mesopores.

Supplementary Materials: The following are available online at http:/ /www.mdpi.com/2073-4344/8/2/82/s1, Table S1: The main products of non-catalytic fast pyrolysis of Kraft lignin determined by Py-GC/MS at $500{ }^{\circ} \mathrm{C}$; Table S2: The main products of catalytic fast pyrolysis of Kraft lignin over HZSM-5 zeolite determined by Py-GC/MS at $500^{\circ} \mathrm{C}$.

Author Contributions: H.C. and J.H. conceived and designed the experiments; X.L. and G.X. performed the experiments; X.L. and Y.B. analyzed the data; Y.B. and H.C. wrote the paper.

Conflicts of Interest: The authors declare no conflict of interest.

\section{References}

1. Vispute, T.P.; Zhang, H.Y.; Sanna, A.; Xiao, R.; Huber, G.W. Renewable Chemical Commodity Feedstocks from Integrated Catalytic Processing of Pyrolysis Oils. Science 2010, 330, 1222-1227. [CrossRef] [PubMed]

2. Liu, C.J.; Wang, H.M.; Karim, A.M.; Sun, J.M.; Wang, Y. Catalytic fast pyrolysis of lignocellulosic biomass. Chem. Soc. Rev. 2014, 43, 7594-7623. [CrossRef] [PubMed]

3. Cheng, Y.T.; Wang, Z.P.; Gilbert, C.J.; Fan, W.; Huber, G.W. Production of p-Xylene from Biomass by Catalytic Fast Pyrolysis Using ZSM-5 Catalysts with Reduced Pore Openings. Angew. Chem. Int. Ed. 2012, 51, 11097-11100. [CrossRef] [PubMed] 
4. Chu, S.; Subrahmanyam, A.V.; Huber, G.W. The pyrolysis chemistry of a beta-O-4 type oligomeric lignin model compound. Green Chem. 2013, 15, 125-136. [CrossRef]

5. Patwardhan, P.R.; Brown, R.C.; Shanks, B.H. Understanding the Fast Pyrolysis of Lignin. ChemSusChem 2011, 4, 1629-1636. [CrossRef] [PubMed]

6. Rezaei, P.S.; Shafaghat, H.; Daud, W.M.A.W. Aromatic hydrocarbon production by catalytic pyrolysis of palm kernel shell waste using a bifunctional Fe/HBeta catalyst: Effect of lignin-derived phenolics on zeolite deactivation. Green Chem. 2016, 18, 1684-1693. [CrossRef]

7. Wang, K.G.; Kim, K.H.; Brown, R.C. Catalytic pyrolysis of individual components of lignocellulosic biomass. Green Chem. 2014, 16, 727-735. [CrossRef]

8. Hoff, T.C.; Gardner, D.W.; Thilakaratne, R.; Proano-Aviles, J.; Brown, R.C.; Tessonnier, J.P. Elucidating the effect of desilication on aluminum-rich ZSM-5 zeolite and its consequences on biomass catalytic fast pyrolysis. Appl. Catal. A Gen. 2017, 529, 68-78. [CrossRef]

9. Hoff, T.C.; Gardner, D.W.; Thilakaratne, R.; Wang, K.G.; Hansen, T.W.; Brown, R.C.; Tessonnier, J.P. Tailoring ZSM-5 Zeolites for the Fast Pyrolysis of Biomass to Aromatic Hydrocarbons. ChemSusChem 2016, 9, 1473-1482. [CrossRef] [PubMed]

10. Puertolas, B.; Veses, A.; Callen, M.S.; Mitchell, S.; Garcia, T.; Perez-Ramirez, J. Porosity-Acidity Interplay in Hierarchical ZSM-5 Zeolites for Pyrolysis Oil Valorization to Aromatics. ChemSusChem 2015, 8, 3283-3293. [CrossRef] [PubMed]

11. Jia, L.Y.; Raad, M.; Hamieh, S.; Toufaily, J.; Hamieh, T.; Bettahar, M.M.; Mauviel, G.; Tarrighi, M.; Pinard, L.; Dufour, A. Catalytic fast pyrolysis of biomass: Superior selectivity of hierarchical zeolites to aromatics. Green Chem. 2017, 19, 5442-5459. [CrossRef]

12. Xue, Y.; Zhou, S.; Bai, X.L. Role of Hydrogen Transfer during Catalytic Copyrolysis of Lignin and Tetralin over HZSM-5 and HY Zeolite Catalysts. ACS Sustain. Chem. Eng. 2016, 4, 4237-4250. [CrossRef]

13. Yu, Y.Q.; Li, X.Y.; Su, L.; Zhang, Y.; Wang, Y.J.; Zhang, H.Z. The role of shape selectivity in catalytic fast pyrolysis of lignin with zeolite catalysts. Appl. Catal. A Gen. 2012, 447-448, 115-123. [CrossRef]

14. Ma, Z.Q.; Ghosh, A.; Asthana, N.; van Bokhoven, J. Optimization of the Reaction Conditions for Catalytic Fast Pyrolysis of Pretreated Lignin over Zeolite for the Production of Phenol. Chemcatchem 2017, 9, 954-961. [CrossRef]

15. Custodis, V.B.F.; Karakoulia, S.A.; Triantafyllidis, K.S.; van Bokhoven, J.A. Catalytic Fast Pyrolysis of Lignin over High-Surface-Area Mesoporous Aluminosilicates: Effect of Porosity and Acidity. ChemSusChem 2016, 9, 1134-1145. [CrossRef] [PubMed]

16. Ma, B.; Zhao, C. High-grade diesel production by hydrodeoxygenation of palm oil over a hierarchically structured Ni/HBEA catalyst. Green Chem. 2015, 17, 1692-1701. [CrossRef]

17. Li, N.N.; Bi, Y.D.; Xia, X.Q.; Chen, H.; Hu, J.L. Hydrodeoxygenation of Methyl Laurate over Ni Catalysts Supported on Hierarchical HZSM-5 Zeolite. Catalysts 2017, 7, 383. [CrossRef]

18. Hiroshi, M.; Toshiyuki, Y.; Hiroyuki, I.; Seitaro, N.; Junko, N.K.; Takashi, T. Effect of desilication of H-ZSM-5 by alkali treatment on catalytic performance in hexane cracking. Appl. Catal. A Gen. 2012, 449, 188-197.

19. Van Aelst, J.; Verboekend, D.; Philippaerts, A.; Nuttens, N.; Kurttepeli, M.; Gobechiya, E.; Haouas, M.; Sree, S.P.; Denayer, J.F.M.; Martens, J.A. Catalyst Design by $\mathrm{NH}_{4} \mathrm{OH}$ Treatment of USY Zeolite. Adv. Funct. Mater. 2015, 25, 7130-7144. [CrossRef]

20. Li, J.; Li, X.; Zhou, G.Q.; Wang, W.; Wang, C.W.; Komarneni, S.; Wang, Y.J. Catalytic fast pyrolysis of biomass with mesoporous ZSM-5 zeolites prepared by desilication with $\mathrm{NaOH}$ solutions. Appl. Catal. A Gen. 2014, 470, 115-122. [CrossRef]

(C) 2018 by the authors. Licensee MDPI, Basel, Switzerland. This article is an open access article distributed under the terms and conditions of the Creative Commons Attribution (CC BY) license (http:/ / creativecommons.org/licenses/by/4.0/). 